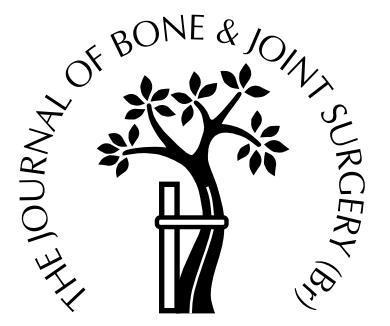

\title{
Observer reliability in the arthroscopic classification of osteoarthritis of the knee
}

\author{
B. H. Brismar, T. Wredmark, T. Movin, J. Leandersson, O. Svensson \\ From Huddinge University Hospital, Stockholm, Sweden
}

$\mathbf{W}$ e studied 19 videotaped knee arthroscopies in 19 patients with mild to moderate osteoarthritis (OA) of the knee in order to compare the intraobserver and interobserver reliability and the patterns of disagreement between four orthopaedic surgeons. The classifications of OA of Collins, Outerbridge and the French Society of Arthroscopy were used. Intraobserver and interobserver agreements using kappa measures were 0.42 to 0.66 and 0.43 to 0.49 , respectively. Only $6 \%$ to $8 \%$ of paired intraobserver classifications differed by more than one category. Observer-specific disagreement was evident both within and between observers. A small, but significant, occasional variation was also seen. Although reliability may improve by an analysis of disagreement, it appears that the arthroscopic grading of early osteoarthritic lesions is inexact.

J Bone Joint Surg [Br] 2002;84-B:42-7.

Received 24 August 2000; Accepted after revision 14 May 2001

Osteoarthritis (OA) is a common endpoint for many joint disorders. It leads to a progressive loss of articular cartilage and remodelling of subchondral bone. Traditionally, OA of the knee has been defined as narrowing of the joint space on radiographs combined with appropriate clinical signs. There is, however, no simple relationship between symptoms and pathology. Furthermore, the clinical value of grading early OA is uncertain, except for preoperative assessment before tibial osteotomy or unicompartmental replacement. For studies involving biochemical markers or chondroprotective agents, the value of the interpretation of the early grading of $\mathrm{OA}$ is more obvious.

B. H. Brismar, MD, Consultant Orthopaedic Surgeon

T. Wredmark, PhD, Associate Professor

T. Movin, PhD, Consultant Orthopaedic Surgeon

J. Leandersson, PhD, Consultant Orthopaedic Surgeon

O. Svensson, PhD, Professor

Department of Orthopaedic Surgery, Huddinge University Hospital, Karolinska Institute, S-141 86 Stockholm, Sweden.

Correspondence should be sent to Dr B. H. Brismar.

(C)2002 British Editorial Society of Bone and Joint Surgery 0301-620X/02/111660\$2.00
The radiological classification of $\mathrm{OA}$ is imprecise, especially in the early stages. In a study of patients with chronic knee pain and considerable narrowing of the tibiofemoral joint space, up to $33 \%$ had normal articular cartilage at arthroscopy. ${ }^{1}$ In another study, seven of 17 patients with advanced tibiofemoral and/or patellofemoral OA seen at arthroscopy had normal radiological findings. ${ }^{2}$ Similar results have been found in other studies." Arthroscopy allows a more detailed description to be made of the depth and extent of the lesions, and the detection of subtle changes such as cartilage softening, fibrillation and tangential flaking. Several classifications of the pathology of articular cartilage have been proposed, such as that of Collins ${ }^{5}$ which is based on autopsy material, or of Outerbridge ${ }^{6}$ which is determined by the findings at arthrotomy. These classifications are based on the depth and distribution of lesions. Recently, more elaborate systems have been proposed $^{7,8}$ which include assessment of the depth, size and location of the lesions. Our aim was to compare intraobserver and interobserver reliability by using three of these classifications and to analyse the nature of any disagreement.

\section{Patients and Methods}

Four orthopaedic surgeons examined 19 videotaped arthroscopies of 19 consecutive patients with a mean age of 46 years (27 to 74) who had disorders of articular cartilage. All the tapes had been recorded by one of the observers at least two months before the first grading session. Each compartment was recorded for one minute starting with the patellofemoral followed by the medial and lateral compartments. All surfaces had been probed to determine soft areas. The arthroscopies were coded, shown in a random order, and assessed individually on two separate occasions, two months apart. Three different classification systems were used: that of Outerbridge, ${ }^{6}$ that of the French Society of Arthroscopy (SFA) ${ }^{8}$ and a modified Collins classification. ${ }^{5}$ The worst lesion on each articular surface was assessed using the Outerbridge and Collins classifications. The SFA grade, location, size and form of cartilage pathology were recorded on an outline of a human knee. Table I shows the classification systems used; 114 surfaces were graded at each session (19 patients with six surfaces each). 
Table I. Outline of the classification systems used for OA of the knee

\begin{tabular}{|c|c|c|c|}
\hline Grade & Modified Collins ${ }^{5}$ & Outerbridge $^{6}$ & SFA $^{8}$ \\
\hline 0 & Normal cartilage & Normal cartilage & Normal cartilage \\
\hline$S$ & Softening of cartilage & Not applicable & Not applicable \\
\hline 1 & $\begin{array}{l}\text { Destruction of superficial cartilage, } \\
\text { confined to areas of greatest } \\
\text { pressure and movement - } \\
\text { tangential flaking, early fibrillation, } \\
\text { shallow pits or grooves }\end{array}$ & $\begin{array}{l}\text { Softening and swelling } \\
\text { of the cartilage }\end{array}$ & $\begin{array}{l}\text { Swelling } \\
\text { and/or } \\
\text { softening }\end{array}$ \\
\hline 2 & $\begin{array}{l}\text { More extensive destruction of } \\
\text { cartilage still confined to areas of } \\
\text { pressure and movement but } \\
\text { not denuding bone. Deep fibrillation } \\
\text { and significant loss of cartilage substance }\end{array}$ & $\begin{array}{l}\text { Fragmentation and } \\
\text { fissuring in an area } \\
0.5 \text { inches }(1.27 \mathrm{~cm}) \text { or less } \\
\text { in diameter }\end{array}$ & Superficial fibrillation \\
\hline 3 & $\begin{array}{l}\text { Total loss of cartilage in one or } \\
\text { more areas of pressure with exposure } \\
\text { and, usually, eburnation of bone. } \\
\text { Widespread fibrillation and flaking } \\
\text { of the remaining cartilage. Areas } \\
\text { of unaffected cartilage in those } \\
\text { parts least exposed to pressure and } \\
\text { movement }\end{array}$ & $\begin{array}{l}\text { Fragmentation and } \\
\text { fissuring in an area } 0.5 \text { inches } \\
(1.27 \mathrm{~cm}) \text { or more in } \\
\text { diameter }\end{array}$ & $\begin{array}{l}\text { Deep fibrillation } \\
\text { down to bone }\end{array}$ \\
\hline 4 & $\begin{array}{l}\text { Complete loss of cartilage from large areas } \\
\text { of the joint surface. Eburnation } \\
\text { of exposed bone }\end{array}$ & $\begin{array}{l}\text { Erosion of cartilage } \\
\text { down to bone }\end{array}$ & $\begin{array}{l}\text { Exposure of subchondral } \\
\text { bone }\end{array}$ \\
\hline
\end{tabular}
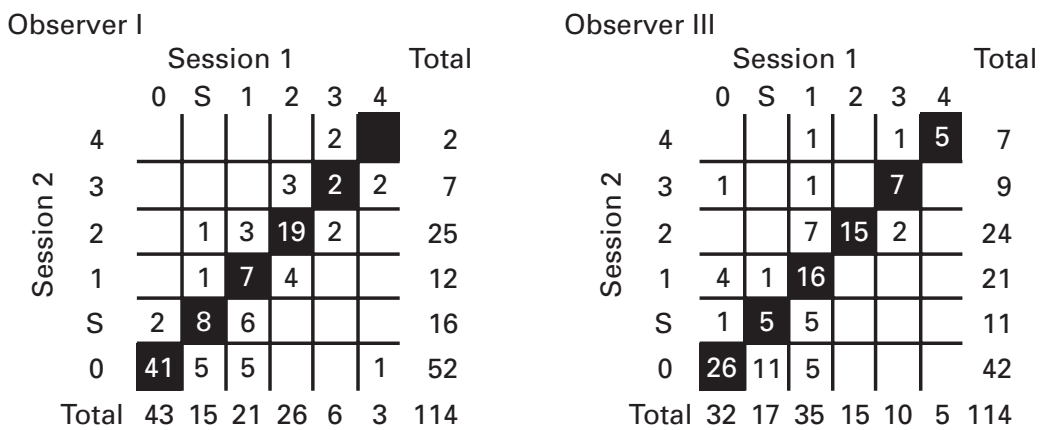

Fig. 1

The distribution of paired classifications for the worst Collins grade. The shaded diagonal represents surfaces with full agreement at both examinations. Those with disagreement are distributed around this line.

Statistical analysis. The ratings were plotted on a contingency table which showed the distribution of paired classifications (Fig. 1). The coefficient kappa (к), which is the measure of agreement beyond that expected by chance alone, was calculated. $\kappa$ values exceeding 0.75 were considered as excellent, 0.4 to 0.75 as fair to good, and less than 0.4 as poor. $^{9}$ As the value does not distinguish between occasional and systematic disagreement, we also evaluated the patterns of disagreement within and between observers. ${ }^{10-12}$ A different distribution of the categories used between two assessments, so-called marginal heterogeneity, suggests systematic disagreement. This can be seen by plotting the sets of cumulative proportions against each other to yield a relative operator characteristic (ROC) curve (Figs 2, 3 and 4). With total agreement the ROC curve is the diagonal of identical co-ordinates. A curve located to one or other side of the diagonal indicates systematic overestimation or underestimation (bias). This bias can be quantified by measuring the relative position (RP). An Sshaped ROC curve indicates that the concentration of classification differs between the two assessments made on the same objects. This can be quantified by measuring the relative concentration (RC). The possible values for RP and $\mathrm{RC}$ range between -1 and +1 . Values close to zero represent a negligible change from one session to another, or between observers, a positive value for RP indicates a systematic change in the use of the scale from a lower to a higher category and a negative RP, a change from a higher to a lower category. The RC will be positive if the categorisation of the second session concentrates more towards the central part of the scale when compared with that at the first session. The RC will be negative if the categorisation changes towards the periphery of the scale. Besides systematic disagreement there will often be occasional variations 


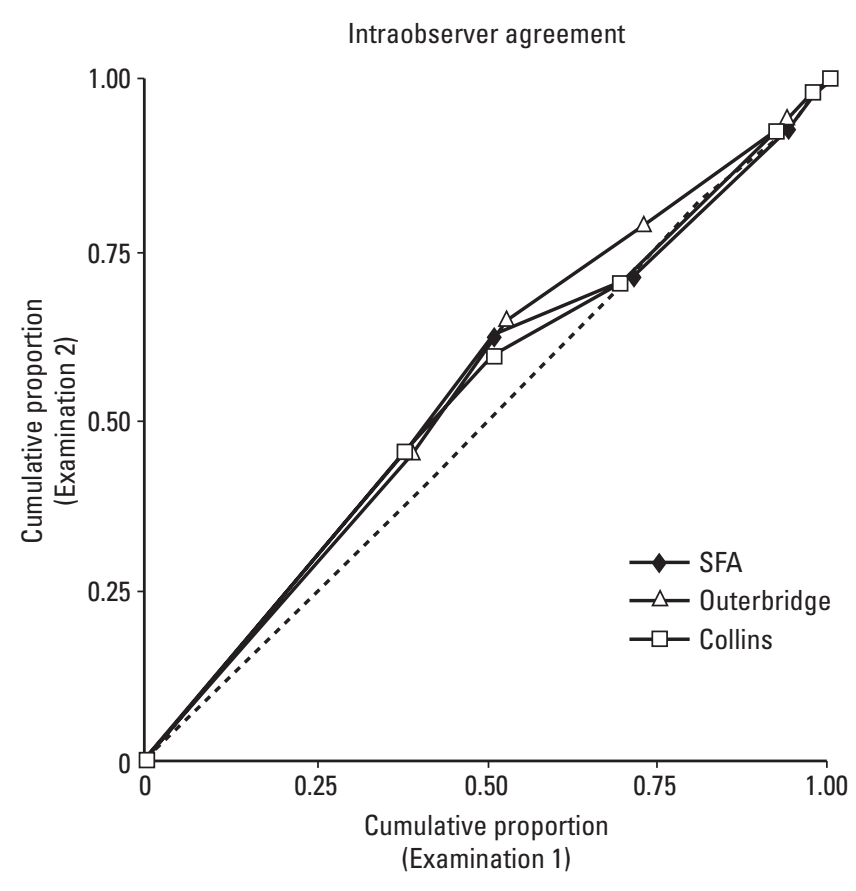

Fig. 2

ROC curves for systematic differences between examinations one and two for observer I. The dotted line represents complete agreement.

in the classification of the same object. This can be estimated from the relative rank variance (RV), which is always less than or equal to one. The smaller the RV, the less is the occasional variation between repeated classifications. We tested the null hypothesis that there was no systematic disagreement in $\mathrm{RP}$ or $\mathrm{RC}(\mathrm{RP}=0, \mathrm{RC}=0)$ and no occasional variability of RV $(\mathrm{RV}=0)$ for classifications made by either each observer at two examinations or two observers at the second examination.

\section{Results}

Intraobserver reliability. Most articular surfaces showed little or no OA (Table II). Normal cartilage (grade 0) and advanced changes (grade 4) were easier to classify (mean intraobserver agreement $81 \%$ ) than the intermediate categories S, 1, 2 and 3 (mean intraobserver agreement 65\%) when the Collins classification was used. Of the paired intraobserver classification $6 \%$ (SFA) to $8 \%$ (Collins) differed by more than one category. Intraobserver agreement on all surfaces ranged from 0.55 to $0.75(\kappa=0.42$ to 0.66$)$. Intraobserver disagreement was evident for observers I, III and IV (Table III). Observer I systematically used lower categories at the second examination regardless of the classification used. This is shown by the negative RP values and the shape of the ROC curves in Figure 2. Observer III systematically concentrated classifications towards the periphery of the Collins and SFA scales at examination two compared with examination one. This is shown by the Sshaped ROC curves (Fig. 3) and the negative RC values

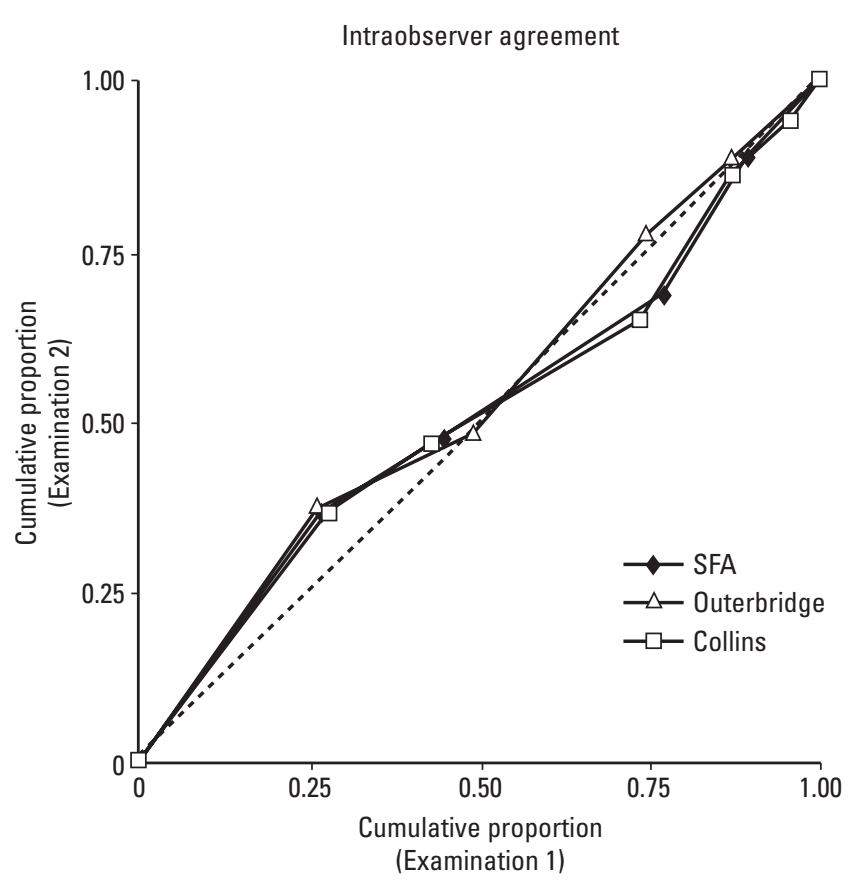

Fig. 3

ROC curves for systematic differences between examinations one and two for observer III. The dotted line represents complete agreement.

(RC -0.152, $\mathrm{p}=0.001$ and $\mathrm{RC}-0.163, \mathrm{p}=0.002)$. Observer IV systematically concentrated classifications towards the centre of the SFA scale $(\mathrm{RC}=0.086, \mathrm{p}=0.03)$. The nonzero RV values in Table III indicate additional variability unexplained by the bias. As an example, the RV value for observer III using the Outerbridge classification was 0.064 and the $95 \%$ confidence interval (CI) did not cover $\mathrm{RV}=0$. This means that part of the variability in classifications was due to non-systematic disagreement.

Interobserver reliability. The overall percentage agreement was $59 \%$ using the Collins classification $(\kappa=0.45)$, $61 \%$ with the Outerbridge classification $(\kappa=0.47)$, and $62 \%$ when the SFA scale was used $(\kappa=0.49)$. Table IV and the ROC curves in Figure 4 show that observers II, III and IV disagreed with observer I when using the Collins, SFA and Outerbridge classifications. Observer III systematically used higher categories than observer I when using the Collins $(\mathrm{RP}=0.12, \mathrm{p}=0.002)$, Outerbridge $(\mathrm{RP}=0.13$, $\mathrm{p}=0.001)$ and SFA classifications $(\mathrm{RP}=0.11, \mathrm{p}=0.003)$. These systematic disagreements in position are reflected by the ROC curves in Figure 4. Observers I and IV showed a similar disagreement when using the Outerbridge classification $(\mathrm{RP}=0.12, \mathrm{p}<0.001)$. Disagreement on the Collins and SFA classifications mainly depended on a systematic disagreement in relative concentration $(\mathrm{RC}=0.17$, $\mathrm{p}<0.001$ and $\mathrm{RC}=0.17, \mathrm{p}<0.001)$. Finally, a significant occasional interobserver disagreement was found in six of nine comparisons. This reflected a random dispersion of observations which could not be explained by the interobserver bias. 

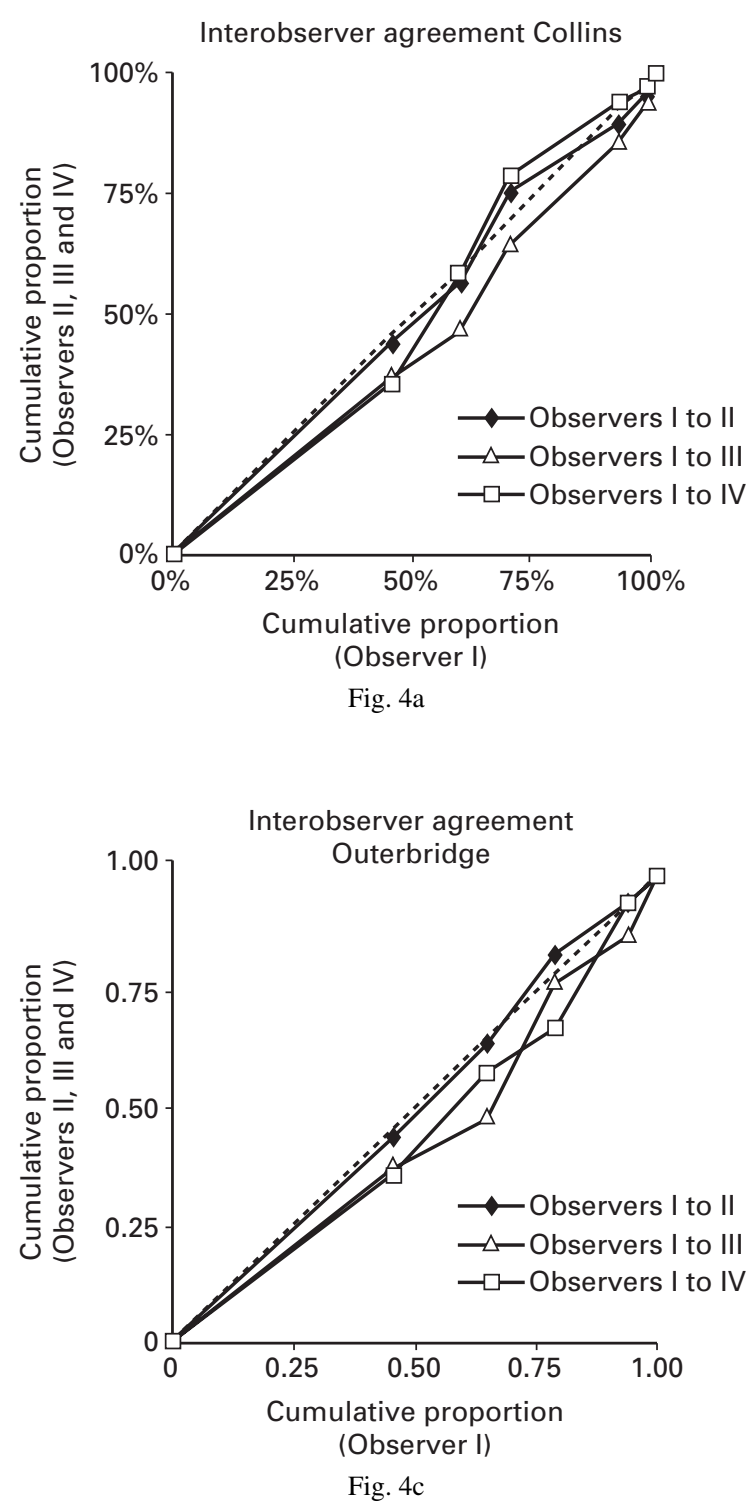

Analysis of the worst degree of OA present revealed similar results with intraobserver agreement ranging from 0.53 to 0.79 ( $\kappa=0.30$ to 0.71 ) with $3 \%$ to $4 \%$ of paired classifications differing by more than one category. Interobserver agreement ranged from 0.6 to $0.7(\kappa=0.4$ to $0.6)$.

\section{Discussion}

We were not able to discern reliably differences of one grade. Reliability, expressed as an intraobserver $\kappa$ value, was only fair to good, although disagreement seldom exceeded one category. No classification appeared to be superior in this respect. Restricting classification to the worst affected surface did not improve reliability. The number of categories as well as the distribution of abnormality, is likely to affect the result. By adding nearby categories in the Collins classification to a three-category

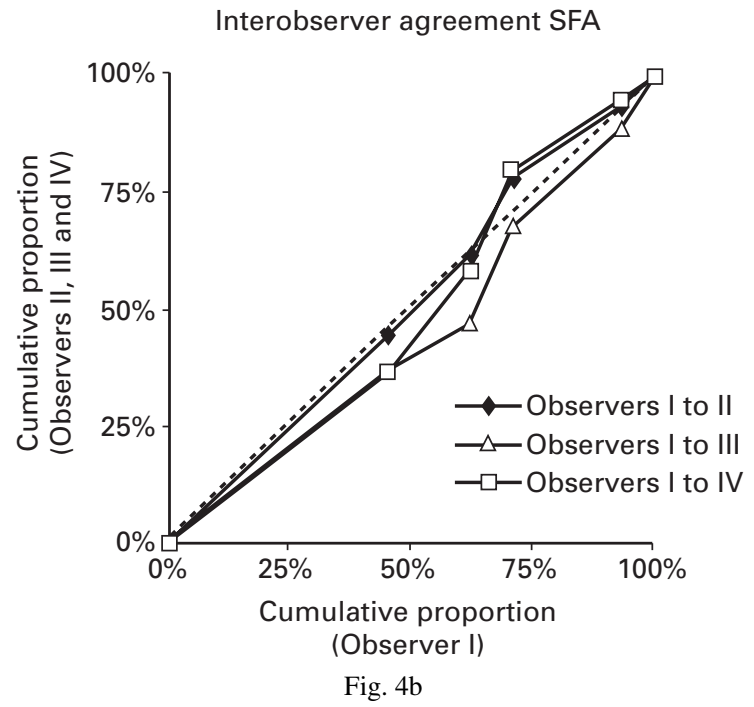

ROC curves for systematic differences between observers II, III and IV compared with observer I at the second examination for a) the Collins b) the SFA and c) the Outerbridge classifications. The dotted line represents complete agreement. scale, reliability was improved from 0.55 to 0.69 (mean intraobserver $\kappa)$. Joints with normal cartilage and those with severe OA changes are likely to yield a higher agreement than joints with intermediate changes. Other published evaluations of orthopaedic radiological classifications ${ }^{13-17}$ have reported similar results.

We have tried to analyse the agreement between observers and the nature of any disagreement. Systematic disagreement is related to the individual examiner, whereas occasional variation is affected by the quality of the method which is used to produce the evaluated material. ${ }^{10} \mathrm{We}$ found that there was intraobserver and interobserver variation in disagreement regardless of the classification scale used. The nature of the variation was observer-specific as illustrated by the results of observers I and III (Table III, Figs 2 and 3). The relatively low RV, illustrated by the limited number of paired classifications which differed by more than one category, indicates a satisfactory arthro- 
scopy. The high number of paired classifications which differed by one category indicates difficulty in discriminating between nearby categories. OA is a continuum of changes. There will always be intermediate patterns which can be classified into more than one group. Agreement may

Table II. Distribution of OA categories (\%) using the Collins classification $^{5}$. Values are means for all surfaces

\begin{tabular}{lllllll}
\hline & Grade & & & & \\
\cline { 2 - 7 } Observer & $\mathbf{0}$ & S & $\mathbf{1}$ & $\mathbf{2}$ & $\mathbf{3}$ & $\mathbf{4}$ \\
\hline I & 42 & 14 & 14 & 22 & 6 & 2 \\
II & 44 & 12 & 22 & 11 & 7 & 4 \\
III & 32 & 12 & 25 & 17 & 8 & 5 \\
IV & 37 & 21 & 21 & 12 & 5 & 4 \\
\hline
\end{tabular}

be improved by concentrating on observer-specific variation patterns at a calibration session. No such calibration was done before this study, except a collective read-through of the written classification.

Several authors have advocated the use of scores when assessing the pathology of articular cartilage at arthroscopy. ${ }^{7,8,18}$ The SFA score assesses pathology on a fivecategory ordinal scale. ${ }^{8}$ The score is reached by multiplying the percentage size of each category by a category-specific value and then adding up the sums within the compartment. It has been evaluated in several studies. ${ }^{19-21}$ Ayral et $\mathrm{al}^{19}$ found an interobserver intraclass reliability coefficient $\geq 0.87$ when assessing the pathology of articular cartilage in the medial compartment using the SFA score. Our value

Table III. Intraobserver reliability measures of the three classification systems at two examinations, two months apart. A jack-knife estimate of the standard error is in parentheses. Each p value relates to the null hypotheses that a measure is equal to zero

\begin{tabular}{|c|c|c|c|c|c|}
\hline \multirow{2}{*}{$\begin{array}{l}\text { System of } \\
\text { classification }\end{array}$} & \multirow{2}{*}{$\begin{array}{l}\text { Measure of } \\
\text { variability }\end{array}$} & \multicolumn{4}{|l|}{ Observer } \\
\hline & & I & II & III & IV \\
\hline \multirow[t]{5}{*}{ Collins } & \multirow{2}{*}{$\begin{array}{l}\text { Agreement } \\
\text { value }\end{array}$} & 0.68 & 0.63 & 0.65 & 0.69 \\
\hline & & 0.56 & 0.49 & 0.55 & 0.59 \\
\hline & RV & $0.023(0.016)$ & $0.036(0.027)$ & $0.040(0.021)$ & $0.0084(0.0043)^{*}$ \\
\hline & $\mathrm{RP}$ & $-0.072(0.028) \dagger$ & $0.023(0.038)$ & $-0.011(0.034)$ & $0.011(0.024)$ \\
\hline & $\mathrm{RC}$ & $-0.066(0.042)$ & $-0.039(0.054)$ & $-0.152(0.045) \ddagger$ & $0.046(0.037)$ \\
\hline \multirow[t]{5}{*}{ Outerbridge } & \multirow{2}{*}{$\begin{array}{l}\text { Agreement } \\
\text { value }\end{array}$} & 0.72 & 0.62 & 0.55 & 0.75 \\
\hline & & 0.62 & 0.47 & 0.42 & 0.66 \\
\hline & $\mathrm{RV}$ & $0.031(0.016)^{*}$ & $0.018(0.008)^{*}$ & $0.064(0.025)^{*}$ & $0.016(0.010)$ \\
\hline & $\mathrm{RP}$ & $-0.104(0.030) \ddagger$ & $0.046(0.032)$ & $-0.060(0.038)$ & $0.029(0.025)$ \\
\hline & $\mathrm{RC}$ & $0.0083(0.045)$ & $-0.061(0.047)$ & $-0.093(0.054)$ & $0.013(0.039)$ \\
\hline \multirow[t]{5}{*}{ SFA } & \multirow{2}{*}{$\begin{array}{l}\text { Agreement } \\
\text { value }\end{array}$} & 0.71 & 0.67 & 0.61 & 0.67 \\
\hline & & 0.61 & 0.54 & 0.50 & 0.56 \\
\hline & RV & $0.024(0.014)$ & $0.020(0.009)^{*}$ & $0.044(0.023)$ & $0.013(0.006)^{*}$ \\
\hline & $\mathrm{RP}$ & $-0.076(0.029) \dagger$ & $0.022(0.029)$ & $-0.015(0.037)$ & $-0.018(0.026)$ \\
\hline & $\mathrm{RC}$ & $-0.077(0.043)$ & $-0.058(0.044)$ & $-0.163(0.051) \dagger$ & $0.086(0.039)^{*}$ \\
\hline
\end{tabular}

* p 0.05

$\dagger \mathrm{p} \quad 0.01$

$+\mathrm{p} \quad 0.001$

Table IV. Interobserver reliability measures of all three classification systems at the second examination. A jackknife estimate of the standard error is in parentheses. Each p value relates to the null hypothesis that a measure is equal to zero

\begin{tabular}{|c|c|c|c|c|}
\hline \multirow{2}{*}{$\begin{array}{l}\text { System of } \\
\text { classification }\end{array}$} & \multirow{2}{*}{$\begin{array}{l}\text { Measure of } \\
\text { variability }\end{array}$} & \multicolumn{3}{|l|}{ Observer } \\
\hline & & I and II & I and III & I and IV \\
\hline Collins & $\begin{array}{l}\text { Percentage agreement } \\
\quad \text { value } \\
\text { RV } \\
\text { RP } \\
\text { RC }\end{array}$ & $\begin{array}{l}0.61 \\
0.46 \\
0.051(0.039) \\
0.0093(0.038) \\
0.021(0.038)\end{array}$ & $\begin{array}{l}0.66 \\
0.54 \\
0.070(0.031)^{*} \\
0.1220 .038) \dagger \\
-0.021(0.050)\end{array}$ & $\begin{array}{l}0.61 \\
0.48 \\
0.041(0.033) \\
0.030(0.041) \\
0.173(0.044) \ddagger\end{array}$ \\
\hline Outerbridge & $\begin{array}{l}\text { Percentage agreement } \\
\text { value } \\
\text { RV } \\
\text { RP } \\
\text { RC }\end{array}$ & $\begin{array}{l}0.68 \\
0.56 \\
0.035(0.015)^{*} \\
0.0035(0.034) \\
0.040(0.043)\end{array}$ & $\begin{array}{l}0.60 \\
0.46 \\
0.067(0.025) \dagger \\
0.131(0.039) \ddagger \\
-0.016(0.052)\end{array}$ & $\begin{array}{l}0.66 \\
0.54 \\
0.031(0.012) \\
0.119(0.034) \ddagger \\
-0.0035(0.052)\end{array}$ \\
\hline SFA & $\begin{array}{l}\text { Percentage agreement } \\
\quad \text { value } \\
\mathrm{RV} \\
\mathrm{RP} \\
\mathrm{RC}\end{array}$ & $\begin{array}{l}0.70 \\
0.58 \\
0.036(0.018)^{*} \\
-0.014(0.037) \\
0.060(0.042)\end{array}$ & $\begin{array}{l}0.67 \\
0.55 \\
0.068(0.026) \dagger \\
0.113(0.038) \dagger \\
0.017(0.047)\end{array}$ & $\begin{array}{l}0.62 \\
0.49 \\
0.046(0.019) \dagger \\
0.032(0.038) \\
0.167(0.046) \ddagger\end{array}$ \\
\hline $\begin{array}{ll}* \mathrm{p} & 0.05 \\
\dagger \mathrm{p} & 0.01 \\
\div \mathrm{p} & 0.001\end{array}$ & & & & \\
\hline
\end{tabular}


was 0.58. Their patients, however, had a different distribution of change. Three of five patients had severe OA and the remaining two a moderate degree. Most of our patients had low-grade changes. It is questionable whether the calculation of an intraclass correlation coefficient is appropriate since the score is derived from ordinal values. It is equally questionable whether different grades can be added together since grade 1 is not necessarily half of grade 2 or one-third of grade 3 , etc. An ordinal scale, by definition, has an unknown class-to-class distance. ${ }^{22}$ Multiplying the grades by the size of the lesions does not decrease any error. In any event, the clinical significance of the depth of a lesion versus its area and distribution is unknown.

The purpose of scoring is to obtain one value which represents the multidimensional changes in the articular cartilage throughout the joint. Hypothetically, this value can be related to other variables such as biochemical markers, clinical signs and treatment outcome. Such a value must be easily defined either as a number on an ordinal scale or as a continuous value. In the case of arthroscopy a value would be categorical in most instances. One option would be to choose the worst lesion detected to represent the state of the whole joint. This method seems to be reasonable for joints which demonstrate a wide distribution of changes, as long as the low resolution of one-grade differences is borne in mind. An alternative approach could be the use of MRI to assess quantitatively disruption of articular cartilage. Yet another would be to create an ordinal scale in which the depth, size and distribution of lesions were specified within each category. ${ }^{23}$ A detailed classification of OA does not appear to add greatly to clinical decision-making, but for research purposes, an improved classification system is required.

We thank Professor Elisabeth Svensson, Department of Statistics (ESA), Örebro University for statistical advice.

This study was supported by the Anna-Greta Crafoord's Foundation for Rheumatological Research, Gun and Bertil Stohne's Foundation, King Gustaf V:s 80 years Anniversary Foundation, Loo and Hans Ostermans Foundation for Medical Research, the Swedish Medical Association, the Swedish Medical Research Council (proj. no 12231), and the Swedish Rheumatic Association.

No benefits in any form have been received or will be received from a commercial party related directly or indirectly to the subject of this article.

\section{References}

1. Fife RS, Brandt KD, Braunstein EM, et al. Relationship between arthroscopic evidence of cartilage damage and radiographic evidence of joint space narrowing in early osteoarthritis of the knee. Arthritis Rheum 1991;34:377-82.
2. Brandt KD, Fife RS, Braunstein EM, Katz B. Radiographic grading of the severity of knee osteoarthritis: relation of the Kellgren and Lawrence grade to a grade based on joint space narrowing, and correlation with arthroscopic evidence of articular cartilage degeneration. Arthritis Rheum 1991;34:1381-6.

3. Lysholm J, Hamberg P, Gillquist J. The correlation between osteoarthrosis as seen on radiographs and on arthroscopy. Arthroscopy 1987;3:161-5.

4. Blackburn WD Jr, Bernreuter WK, Rominger M, Loose LL. Arthroscopic evaluation of knee articular cartilage: a comparison with plain radiographs and magnetic resonance imaging. J Rheumatol 1994;21:675-9.

5. Collins DH. The pathology of articular and spinal diseases. London: Edward Arnold Co, 1949.

6. Outerbridge RE. The aetiology of chondromalacia patellae. $J$ Bone Joint Surg [Br] 1961;43-B:752-7.

7. Noyes FR, Stabler CL. A system for grading articular cartilage lesions at arthroscopy. Am J Sports Med 1989;17:505-13.

8. Dougados M, Ayral X, Listrat V, et al. The SFA system for assessing articular cartilage lesions at arthroscopy of the knee. Arthroscopy 1994;10:69-77.

9. Fleiss JL. Statistical methods for rates and proportions. 2nd ed. New York, etc: John Wiley \& Sons, 1981.

10. Svensson E, Starmark J-E, Ekholm S, et al. Analysis of interobserver disagreement in the assessment of subarachnoid blood and acute hydrocephalus on CT scans. Neurol Res 1996;18:487-94.

11. Svensson E. Ordinal invariant measures for individual and group changes in ordered categorical data. Stat Med 1998;17:2923-36.

12. Svensson E. Application of a rank-invariant method to evaluate reliability of ordered categorical assessments. J Epidemiol Biostat 1998;3:403-9.

13. Andersen E, Jorgensen LG, Hededam LT. Evans' classification of trochanteric fractures: an assessment of the interobserver and intraobserver reliability. Injury 1990;21:377-8.

14. Thomsen NOB, Overgaard S, Olsen LH, Hansen H, Nielsen ST. Observer variation in the radiographic classification of ankle fractures. J Bone Joint Surg [Br] 1991;73-B:676-8.

15. Sidor ML, Zuckerman JD, Lyon T, et al. The Neer classification system for proximal humeral fractures: an assessment of interobserver reliability and intraobserver reproducibility. J Bone Joint Surg [Am] 1993;75-A:1745-50.

16. Siebenrock KA, Gerber $C$. The reproducibility of classification of fractures of the proximal end of the humerus. J Bone Joint Surg [Am] 1993;75-A:1751-5.

17. Sjoden GO, Movin T, Guntner P, et al. Poor reproducibility of classification of proximal humeral fractures: additional CT of minor value. Acta Orthop Scand 1997;68:239-42.

18. Marshall KW. The case for a simple method of grading osteoarthritis severity at arthroscopy. J Rheumatol 1996;23:582-5.

19. Ayral X, Dougados M, Listrat V, et al. Arthroscopic evaluation of chondropathy in osteoarthritis of the knee. J Rheumatol 1996;23:698-706.

20. Ayral X, Gueguen A, Ike RW, et al. Inter-observer reliability of the arthroscopic quantification of chondropathy of the knee. Osteoarthritis Cartilage 1998;6:160-6.

21. Drape JL, Pessis E, Aulely GR, et al. Quantitative MR imaging evaluation of chondropathy in osteoarthritic knees. Radiology 1998;208:45-55.

22. Merbitz C, Morris J, Grip JC. Ordinal scales and foundations of misinference. Arch Phys Med Rehabil 1989;70:308-12.

23. Dahlberg L, Ryd L, Heinegärd D, Lohmander LS. Proteoglycan fragments in joint fluid: influence of arthrosis and inflammation. Acta Orthop Scand 1992;63:417-23. 